\title{
Curvas de compactação de um Latossolo Vermelho-Amarelo: Com e sem reúso de amostras
}

\author{
Fabricio T. Ramos', Denis T. Ramos' ${ }^{1}$ João C. de S. Maia', \\ Milson E. Serafim² ${ }^{2}$ Emilio C. de Azevedo ${ }^{1}$ \& Márcio W. Roque ${ }^{3}$
}

\begin{abstract}
RESUMO
A curva de compactação do solo é determinada pelo ensaio de Proctor, normal ou modificado, amplamente empregado na engenharia civil; entretanto, seu uso agronômico apresenta limitações já que a configuração da curva parte do reúso de uma única amostra, desconsiderando a estrutura original do solo. Diante disto, objetivou-se avaliar a configuração da curva de compactação a partir do reúso e não reúso de amostras de um Latossolo Vermelho-Amarelo considerando-se diferentes sistemas de manejo. Verificou-se, ao comparar o procedimento com e sem reúso da amostra que, independentemente dos manejos e camadas avaliadas, foram obtidas diferentes curvas de compactação do solo. Por outro lado, o procedimento com reúso aumenta os valores de densidade do solo pela fragmentação dos agregados e reorganização das suas partículas. Portanto, para fins agrícola a curva de compactação é adequadamente caracterizada sem reúso de amostras visto que, neste ensaio, os agregados da amostra não são totalmente fracionados, sejam eles oriundos do solo sob vegetação nativa ou de áreas antropizadas.
\end{abstract}

Palavras-chave: umidade ótima de compactação, densidade máxima de compactação, Proctor normal, estabilidade de agregados, matéria orgânica do solo

\section{Soil compaction curves of an Oxissol: With and without reuse of samples}

\begin{abstract}
The soil compaction curve is determined by the Proctor test, normal or modified, widely used in civil engineering, however, its use has agronomic limitations, since the configuration of the curved part of the reuse of a single sample, disregarding the original soil structure. In this context, the objective of the study was to evaluate the configuration of the compaction curve based on with and without reuse of samples of an Oxissol, considering different management systems. While comparing the procedure with and without reuse of the sample, it was found that regardless of managements and layers evaluated, curves of soil compaction obtained were different. Furthermore, the procedure to reuse samples increases the density of the soil due to fragmentation of the aggregates and reorganization of its particles. Thus, for agricultural purposes, the compaction curve is suitably characterized without reuse of samples, since with this test, the aggregates of the sample, are not fully fractionated, both aggregates from soil under native vegetation or anthropized areas.
\end{abstract}

Key words: optimum moisture for compaction, maximum density of compaction, standard Proctor, aggregate stability, soil organic matter 


\section{INTRODUÇÃO}

A região Centro-Oeste do Brasil vem-se destacando na produção de cereais, leguminosas e oleaginosas, apesar disto, a problemática relacionada à compactação dos solos é uma realidade, ocasionada sobretudo pelo uso intensivo do solo, além da trafegabilidade e preparo acumulativo de máquinas e implementos agrícolas. Quando a estrutura do solo se degrada pode haver, além do decréscimo da matéria orgânica, limitações quanto à resiliência do solo a processos erosivos; menor disponibilidade hídrica e de nutrientes para o desenvolvimento das plantas; redução da porosidade de aeração; aumento da resistência do solo à penetração das raízes e menor ciclagem e mineralização de nutrientes (Hamza \& Anderson, 2005). Essas limitações propiciam o decréscimo do rendimento agrícola e aumentam os custos de produção (Santos et al., 2005; Barzegar et al., 2006).

Várias técnicas podem ser utilizadas para evitar ou reduzir a compactação do solo dentre as quais se destacam: redução da pressão aplicada com o aumento da área de contato dos rodados com solo; manejo do solo em condições ótimas de umidade; redução da intensidade e frequência de tráfego de maquinários; controle do tráfego com base em áreas de acesso; incremento de material orgânico; uso de escarificadores e rotação de cultivos, que incluem plantas com sistema radicular estratificado (Hamza \& Anderson, 2005; Botta et al., 2007). Desta forma e enquanto a compactabilidade de um solo é importante na construção civil, agronomicamente, o excesso, além de degradar sua estrutura, também pode restringir o desenvolvimento das raízes das plantas e a mecanização agrícola (Silva et al., 2006; Reinert et al., 2008).

Uma das técnicas laboratoriais derivada da engenharia geotécnica usada para reproduzir as condições de compactação em obras civis e áreas agrícolas, é o ensaio de Proctor (normal ou modificado). Este ensaio é usado para determinar a curva de compactação do solo (Braida et al., 2006). Agronomicamente, a importância da curva de compactação está relacionada à determinação da umidade ótima de compactação que permite inferir se o solo está com umidade elevada para trafegabilidade pois, se estiver, podem ser aumentadas a densidade do solo e a derrapagem dos rodados, processo que também contribui significativamente para a compactação do solo (Raghavan et al., 1990). Entretanto, quanto à previsibilidade desse método em relação à compactação do solo causada por máquinas agrícolas, as inferências disponíveis são insuficientes para julgar esse tipo de ensaio em laboratório.

Além disto, a natureza do solo pode influenciar significativamente a configuração da curva de compactação, conforme sua composição granulométrica, carbono orgânico e limite de umidade do solo (Aragón et al., 2000; Dias Júnior \& Miranda, 2000; Braida et al., 2006). No entanto, não se sabe o comportamento dessa curva quando se usa uma única amostra de solo (com reúso) para os intervalos de umidade considerados (Braida et al., 2006) ou se usam amostras independentes com conservação dos agregados (sem reuso). Portanto, é um problema que pode caracterizar as curvas de compactação distintas para um mesmo solo pois, hipoteticamente, se acredita que o procedimento de reúso superestima a densidade máxima de compactação do solo pela fragmentação dos agregados e reorganização das suas partículas.

Objetivou-se, então, avaliar a configuração da curva de compactação a partir do reúso e do não reúso de amostras de um Latossolo Vermelho-Amarelo, considerando-se diferentes sistemas de manejo.

\section{Material e Métodos}

As áreas nas quais foram feitas as coletas das amostras de solo, em abril de 2011, estão localizadas no município de Cáceres, região Sudoeste do Estado de Mato Grosso, latitude $16^{\circ} 03^{\prime} 39^{\prime \prime} \mathrm{S}$, longitude $58^{\circ} 19^{\prime} 21^{\prime \prime} \mathrm{W}$ e altitude de $184 \mathrm{~m}$. O clima, pela classificação de Köppen, é tropical úmido (Aw) com temperatura média do mês mais frio superior a $18,0{ }^{\circ} \mathrm{C}$. Apresenta inverno seco e chuvas no verão, com temperatura máxima anual de $31,5^{\circ} \mathrm{C}$ e mínima de $20,1^{\circ} \mathrm{C}$. A pluviosidade anual é de aproximadamente $1317,41 \mathrm{~mm}$, dos quais $76 \%$ se concentram nos meses de novembro a abril. O solo foi classificado como Latossolo Vermelho-Amarelo (EMBRAPA, 2006) com textura argilo-arenosa e relevo plano.

Adotou-se o delineamento experimental inteiramente casualizado, com três níveis de manejo do solo, três camadas de amostragem $(0-0,10,0,10-0,20$ e $0,20-0,30 \mathrm{~m})$ e cinco repetições. Demarcou-se, para cada manejo, uma área aproximada de $2.500 \mathrm{~m}^{2}$ para se proceder à amostragem casualizada.

Os níveis de manejo e seus respectivos históricos foram: (i) cerrado $(\mathrm{CE})$, vegetação primária que, conforme critérios da EMBRAPA (2006) se enquadra na fase cerrado, tipologia Cerradão Tropical Subcaducifólio, tomado como área controle, com serapilheira em superfície e grande quantidade de raízes finas nos primeiros centímetros do solo; (ii) monocultivo de soja (MS) manejada em semeadura direta com remanescentes de resíduos culturais. Após a abertura da área seguiram-se aração e gradagem com plantio de arroz (2002/03). Até a safra 2006/07 foi plantada soja convencional, com safrinha de soja precoce e, em seguida, até 2010/11, milheto (safrinhas). Em 2009 foram feitas escarificações na área até $0,30 \mathrm{~m}$ para amenizar a compactação do solo, conforme diagnóstico de estandes desuniformes, raízes tortuosas, murchamento por veranicos, competição por plantas daninhas e queda na produtividade; (iii) pastagem implantada (PA) com Brachiaria brizantha cv. Marandu, por oito anos, manejada extensivamente com bovinos da raça nelore para engorda, com capacidade média de suporte de 1,5 U.A. ha ${ }^{-1}$, sem controle de lotação e de reentrada animal. A implantação foi feita sem correção química do solo e a semeadura, a lanço, com incorporação por meio de correntão, após duas gradagens. No dia da amostragem a pastagem apresentava desenvolvimento vigoroso com ausência de solo descoberto.

Com vista à realização do ensaio do Proctor Normal foram coletados, em cada ponto amostral (repetição) e por meio de abertura de trincheiras, $8 \mathrm{~L}$ de solo, preservando a estrutura natural dos torrões, acondicionando-os em embalagens plásticas rígidas para o transporte. No laboratório as amostras foram submetidas à secagem ao ar, durante sete dias e destorroadas, rompendo os agregados em suas superfícies de fraqueza; 
posteriormente, as amostras relativas às cinco repetições de cada manejo e camada foram agrupadas formando uma amostra composta e só então passadas em peneira de malha de 4,75 mm, conforme a norma NBR 7182 (ABNT, 1986).

Para determinação da curva de compactação fez-se o umedecimento crescente das amostras com o uso de borrifadores as quais foram acondicionadas, em seguida, em sacos hermeticamente fechados durantes $24 \mathrm{~h}$ para assegurar a homogeneização da umidade. Para melhorar a homogeneidade as amostras foram agitadas após $2 \mathrm{~h}$ de repouso. Para cada camada avaliada foram realizados dois ensaios de Proctor, com e sem reúso do material coletado. Após compactar o solo no corpo de prova duas amostras foram extraídas do seu centro para determinação da umidade gravimétrica. Visando à obtenção das curvas de compactação, os pares de valores umidade (U) e densidade do solo (Ds) foram ajustados por meio de regressão, conforme a equação polinomial quadrática $\left(\mathrm{Ds}=\mathrm{y} 0+\mathrm{aU}-\mathrm{bU}^{2}\right)$ em que y0, b e c são os coeficientes estimados.

Este procedimento de amostra composta foi executado pela inviabilidade operacional de coleta, transporte e processamento de mais de duas toneladas de solo com estrutura preservada, caso fosse viável comparar, estatisticamente, os pares de $\mathrm{U}_{\text {ótima }}$ e $\mathrm{Ds}_{\text {máx }}$ de compactação entre as camadas e os manejos avaliados com e sem reúso de amostra, isto é, consideradas as cinco repetições.

Além disto, foram determinados, referentes a cada ponto e camada amostrada, os seguintes atributos físicos do solo: granulometria e grau de floculação, por meio de material passado na peneira de 2,0 $\mathrm{mm}$ usando-se mesa agitadora por $16 \mathrm{~h}$, pelo método do densímetro de Bouyoucos (EMBRAPA, 1997); matéria orgânica, por oxidação com bicromato de potássio e determinação colorimétrica (EMBRAPA, 1997) e estabilidade de agregados (Beutler et al., 2001). À granulometria do solo seguiu-se a Classificação Norte-Americana (USDA) para separar a fração areia (muito grossa, grossa, média, fina e muito fina) e determinar a curva granulométrica acumulada (porcentagem de massa de solo retido por classe de diâmetro). Esses dados, que apresentaram erros com distribuição normal pelo teste de Shapiro-Wilk $(\mathrm{p}>0,05)$ foram submetidos à análise de variância pelo teste $\mathrm{F}$ (Fischer) e as médias dos manejos comparadas pelo teste Tukey $(\mathrm{P}<0,05)$ (Banzato \& Kronka, 1992).

\section{Resultados E Discussão}

Verificou-se que a hipótese de que o procedimento com reúso de amostras caracteriza curvas distintas para o mesmo solo, é verdadeira pois, independentemente das camadas e dos manejos avaliados, foram observados deslocamento ascendente das curvas e aumento da densidade máxima de compactação $\left(\mathrm{Ds}_{\text {máx }}\right)$. No entanto, por se tratar do mesmo solo praticamente não houve alteração da umidade ótima $\left(U_{\text {ótima }}\right)$ de compactação (Figura 1).

A $U_{\text {ótima }}$ de compactação, assim como a $\mathrm{Ds}_{\text {máx }}$ do solo na área de monocultivo de soja, nas camadas $0-0,10,0,10-0,20$ e 0,20-0,30 m para o ensaio sem reúso de amostra, variou de 0,106 a $0,116 \mathrm{~kg} \mathrm{~kg}^{-1}$ e 1,656 a $1,660 \mathrm{Mg} \mathrm{m}^{-3}$, enquanto com reúso, ambas variaram de 0,107 a $0,116 \mathrm{~kg} \mathrm{~kg}^{-1}$ e 1,689 a 1,707 $\mathrm{Mg} \mathrm{m}^{-3}$, respectivamente.
$\mathrm{Na}$ área de pastagem a $\mathrm{U}_{\text {ótima }}$ assim como a $\mathrm{Ds}_{\text {máx }} \mathrm{de}$ compactação, nas camadas 0-10, 10-20 e 20-30 cm para o ensaio sem reúso de amostra, variou de 0,106 a $0,126 \mathrm{~kg} \mathrm{~kg}^{-1}$ e 1,574 a $1,643 \mathrm{Mg} \mathrm{m}^{-3}$ enquanto com reúso de amostra ambas variaram de 0,112 a $0,129 \mathrm{~kg} \mathrm{~kg}^{-1}$ e 1,655 a $1,729 \mathrm{Mg} \mathrm{m}^{-3}$, respectivamente.

Já na área de cerrado nativo a $\mathrm{U}_{\text {ótima }}$ de compactação, da mesma forma que a $\mathrm{Ds}_{\text {máx }}$ do solo nas camadas $0-0,10,0,10$ 0,20 e 0,20-0,30 m, para o ensaio sem reúso de amostra, variou de 0,110 a $0,108 \mathrm{~kg} \mathrm{~kg}^{-1}$ e 1,574 a $1,634 \mathrm{Mg} \mathrm{m}^{-3}$ enquanto com reúso de amostra, as duas variaram de 0,111 a $0,118 \mathrm{~kg} \mathrm{~kg}^{-1} \mathrm{e}$ 1,659 a $1,712 \mathrm{Mg} \mathrm{m}^{-3}$.

Ao analisar as curvas de compactação sem reúso de amostras observa-se que, em comparação com as amostras com reúso e independentemente das camadas e do manejo, há um deslocamento descendente das curvas (Figura 1). Com base neste fato constata-se, nas curvas de compactação obtidas sem reúso de amostra, a ação do êmbolo do Proctor Normal o que não desfaz, provavelmente, todos os agregados do solo dificultando, então, a expulsão do ar e da água, sobretudo os intra-agregados, mesmo em condição de maior umidade no solo levando a um valor menor de $\mathrm{Ds}_{\max }$ para a área de monocultivo de soja, pastagem e cerrado nativo, independentemente das camadas avaliadas.

Todos os resultados apresentaram erros com distribuição normal pelo teste de Shapiro-Wilk ( $p>0,05)$ (Tabela 1); disto, todos os ajustes obtidos foram significativos $(p<0,05)$, com baixo erro padrão médio de 0,0148 $( \pm 0,0018)$ e explicaram mais de $90 \%$ a variação dos pares de valores de densidade do solo versus umidade gravimétrica $\left(\mathrm{R}^{2}\right)$. Também ambos os coeficientes (y0, a e b) foram significativos a nível de 5\% de probabilidade não havendo intersecção entre os erros padrão dos coeficientes estimados, independentemente das camadas e manejos; conclui-se, portanto, que as curvas com e sem reúso de amostras, são diferentes.

Weirich Neto et al. (2002) e Braida et al. (2006) verificaram, avaliando o comportamento da curva de compactação com reúso de amostras com e sem presença de material orgânico livre, que em baixa condição de umidade do solo o efeito da capilaridade é maior, o que dificulta o rearranjo das partículas do solo. No entanto, conforme se adiciona água a força de adsorção das partículas do solo pelas moléculas de água diminui, facilitando a compressão do solo, até atingir a $\mathrm{Ds}_{\text {máx }}$ de compactação em virtude da expulsão de ar dos vazios do solo ocorrendo, a partir deste ponto, um processo inverso em razão da fluidez e incompressibilidade da água.

Segundo Braida et al. (2006) à medida em que o diâmetro das partículas diminui, a área superficial e suas propriedades relacionadas aumentam significativamente com maior capacidade de retenção de água e maior capacidade das partículas se manterem unidas como pequenos agregados. Desta forma, mais importante do que o percentual das partículas do solo, sua distribuição granulométrica com predomínio de partículas de argila também pode aumentar o teor de $\mathrm{U}_{\text {ótima }}$ de compactação e reduzir a $\mathrm{Ds}_{\text {máx }}$ do solo (Figura 2).

No entanto, por se tratar da mesma classe de solo e embora na área de cerrado nativo na camada de $0-0,10 \mathrm{~m}$, que apresentou um leve decréscimo de partículas mais finas, não 

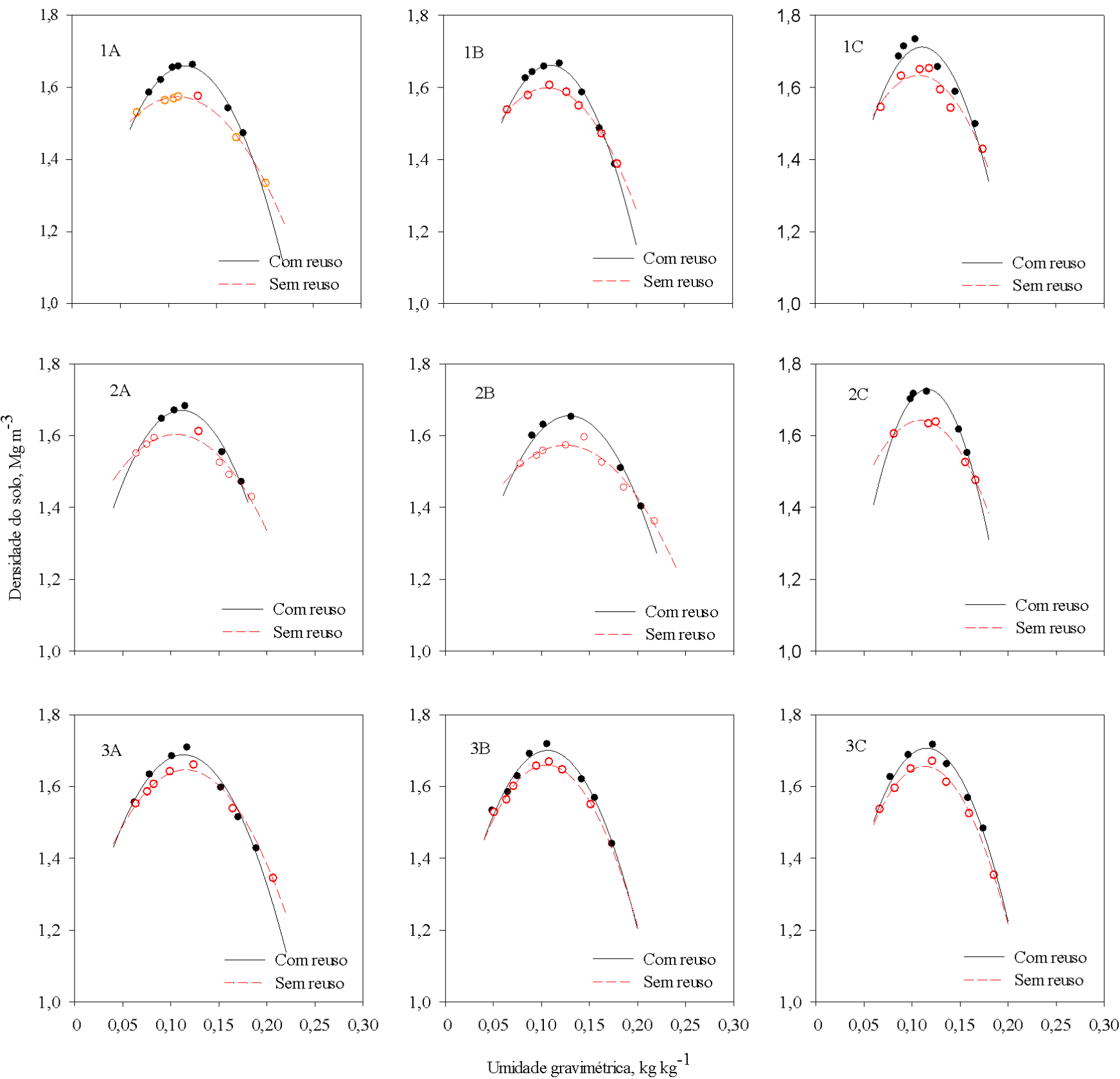

Figura 1. Curvas de compactação obtidas pelo teste de Proctor Normal, com e sem reúso de amostras, sob cerrado nativo 1A, 1B, 1C (0-0,10, 0,10-0,20 e 0,20-0,30 m), pastagem 2A, 2B, 2C (0-0,10, 0,10-0,20 e 0,20-0,30 m) e monocultivo de soja $3 \mathrm{~A}, 3 \mathrm{~B}$ e $3 \mathrm{C}(0-0,10,0,10-0,20$ e $0,20-0,30 \mathrm{~m})$, respectivamente

houve alterações significativas referentes às partículas de argila do solo, Tabela 2 , justificando a pouca variação da umidade ótima de compactação $\left(\mathrm{U}_{\text {ótima }}\right)$ anteriormente relatada, quando comparada com a do ensaio com e sem reúso de amostras.

Sendo assim, o procedimento de reúso de amostra, embora não ocasione uma variação clara no teor da $U_{\text {ótima }}$ de compactação, superestimou nitidamente a Ds máx de compactação, provavelmente pela fragmentação dos agregados e uma nova reorganização das partículas do solo. A consequência disto no âmbito agronômico está relacionada à determinação e ao uso de valores limites de densidade do solo acima dos valores de $D_{\text {máx }}$ de compactação normais para a condição estrutural atual, levando a interpretações errôneas da condição física do solo. Por exemplo, o indicador físico do solo, denominado grau de compactação ou densidade relativa do solo, é determinado pela relação entre a densidade atual do solo no campo e a Ds maxx $_{\text {de }}$ compactação obtida pelo ensaio de Proctor normal (Klein, 2006).

Por outro lado, como experimentos em vasos partem do princípio da determinação da $\mathrm{Ds}_{\text {máx }}$ de compactação para ajustar níveis decrescentes relativos de compactação para cultivo de plantas (Silva et al., 2006) tais limites podem estar superestimados por desconsiderarem o efeito dos agregados na redução deste limite máximo, gerando uma condição possivelmente menos representativa da estrutura atual de um solo, sobretudo se houver grande proporção de macroagregados ( $>2 \mathrm{~mm}$ ). Além disto, como a trafegabilidade e o preparo do solo em condições de umidade excessiva podem acelerar sua 
Tabela 1. Resultados obtidos no ajuste dos dados oriundos do teste de Proctor, com e sem reúso de amostras, sob diferentes manejos do solo

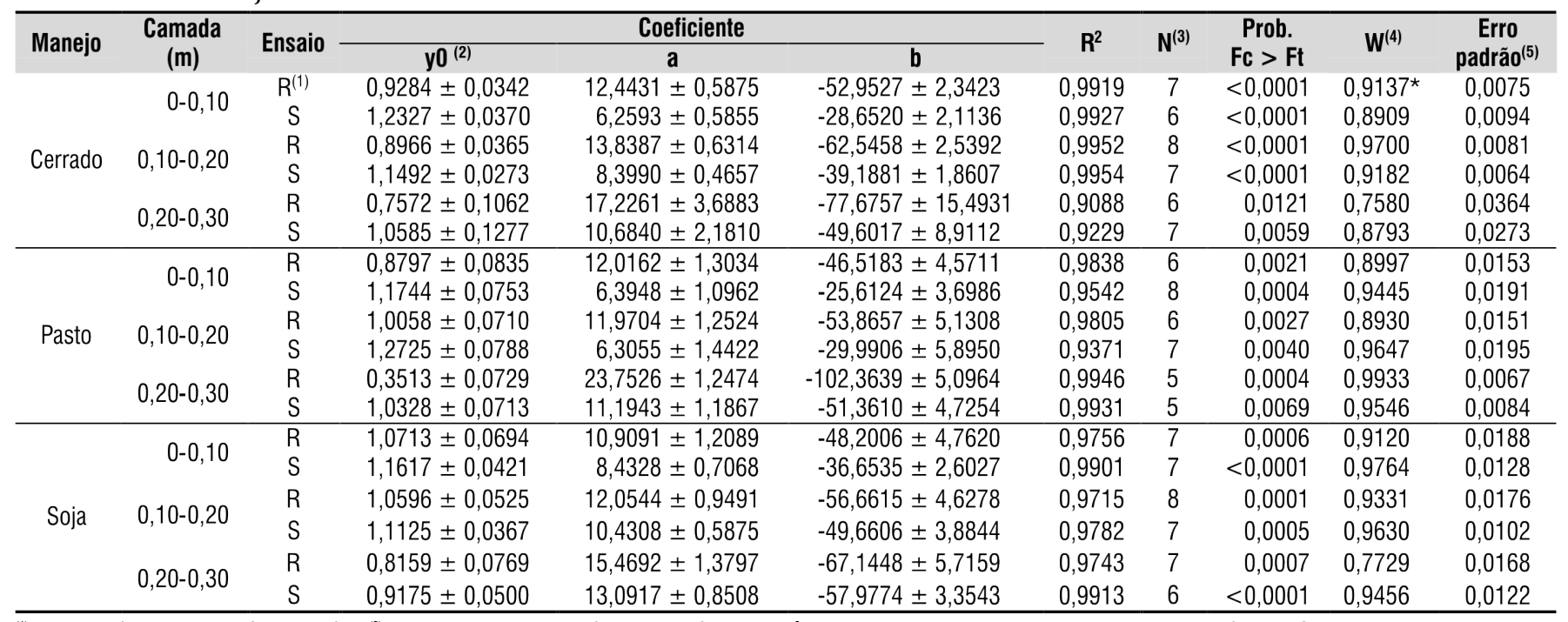

(1) $\mathrm{R}$ - com reúso de amostra, S - sem reúso; (2) Utilizou-se o modelo quadrático (Ds = y0 + aU - bU²), em que: Ds - densidade do solo, U - umidade gravimétrica e y0, a e b - coeficientes estimados; ${ }^{(3)} \mathrm{N}$ - número de pares de dados usados para ajustar a equação; ${ }^{(4)} \mathrm{W}$ - Teste de normalidade de Shapiro-Wilk $(\mathrm{p}>0,05)$; ${ }^{\text {(5) }}$ Erro padrão da estimativa

A. Diâmetro inferior das partículas $(\mathrm{mm})$
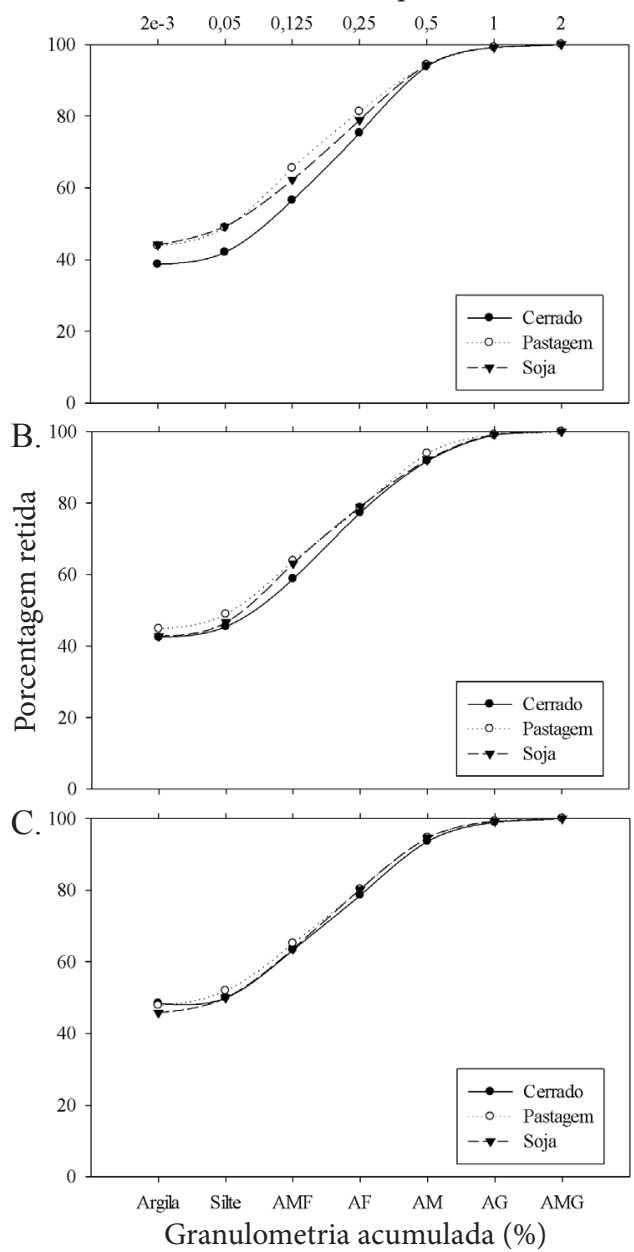

Figura 2. Curva granulométrica de um Latossolo Vermelho-Amarelo sob Cerrado, pastagem e monocultivo de soja, nas camadas 0-0,10 (A), 0,100,20 (B) e 0,20-0,30 m (C). AMF, AF, AM, AG, AMG e $\mathrm{CO}$ se referem à areia muito fina, fina, média, grossa, muito grossa e cascalho, respectivamente
Tabela 2. Valores médios de percentual de argila em um Latossolo Vermelho-Amarelo em função dos diferentes manejos e camadas

\begin{tabular}{llll}
\hline \multirow{2}{*}{ Manejo } & \multicolumn{3}{c}{ Camada (m) } \\
\cline { 2 - 4 } & $\mathbf{0 - \mathbf { 0 , 1 0 }}$ & $\mathbf{0 , 1 0 - 0 , 2 0}$ & $\mathbf{0 , 2 0 - 0 , 3 0}$ \\
Cerrado & \multicolumn{1}{c}{ Argila (\%) } & & \\
Pastagem & $37,07 \mathrm{a}^{1}$ & $42,41 \mathrm{a}$ & $48,41 \mathrm{a}$ \\
Monocultivo de soja & $43,83 \mathrm{a}$ & $44,83 \mathrm{a}$ & $47,83 \mathrm{a}$ \\
$\mathrm{CV}(\%)^{2}$ & $44,13 \mathrm{a}$ & $42,80 \mathrm{a}$ & $45,80 \mathrm{a}$ \\
\hline
\end{tabular}

${ }^{1}$ Médias seguidas da mesma letra na vertical não se diferenciam pelo teste Tukey $(\mathrm{P}<0,05)$; ${ }^{2} \mathrm{CV}(\%)$ - coeficiente de variação

compactação, o uso de valores correspondentes à $\mathrm{Ds}_{\text {máx }}$ de compactação (como medida de monitoramento) determinados com reúso de amostra, pode superestimar a capacidade de suporte do solo uma vez que sem reúso o limite da $\mathrm{Ds}_{\text {máx }}$ é inferior.

Desta forma, na caracterização da curva de compactação sem reúso de amostras o efeito dos agregados no comportamento da curva de compactação do solo pode ser entendido pela comparação entre os diferentes sistemas de manejo e camadas avaliadas, ou seja, primeiro conhecendo o comportamento dos agregados sob condição natural, antes do ensaio do Proctor Normal, Figura 3A; em seguida, o efeito sobre a estabilidade dos agregados após as análises sem reúso, Figura 3B e com reúso de amostra (Figura 3C).

Sob condição natural observou-se clara discriminação entre os manejos, sobremaneira quanto ao declínio da agregação no solo sob monocultivo de soja recentemente escarificado e gradeado em superfície (Figura 3A). Esta redução está relacionada, sem dúvida ao menor conteúdo de matéria orgânica e ao grau de floculação do solo, Tabela 3 , haja vista que sistemas de manejos com pastagem permanente favorecem a formação de agregados estáveis de maior tamanho em relação a sistemas apenas com lavouras devido ao não revolvimento do solo e ao maior acúmulo de carbono orgânico no solo (Salton et al., 2008); ao sistema radicular fasciculado, denso e profundo das gramíneas (Garcia \& Rosolem, 2010); além de estar associado 
Classes de agregados ( $\mathrm{mm}$ )

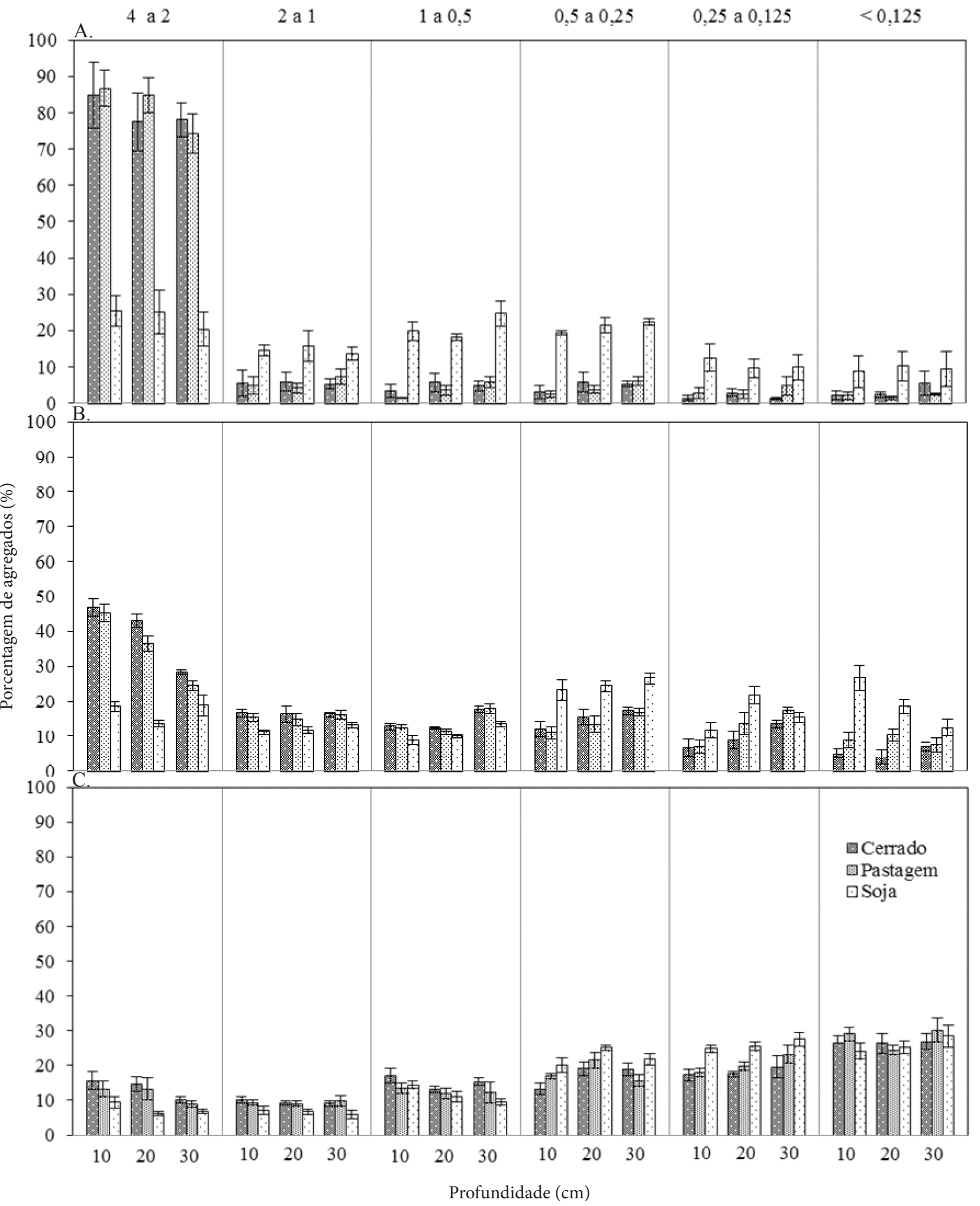

As barras indicam os valores de erro padrão da média em que sua sobreposição denota ausência de diferença entre as médias dos manejos

Figura 3. Porcentagem de agregados de um Latossolo Vermelho-Amarelo via tamisamento úmido sob condição natural $(\mathrm{A})$ sem reúso $(\mathrm{B})$ e com reúso de amostra (C)

a hifas fúngicas, que favorecem a agregação físico-química do solo (Tisdall, 1994).

Devido a esses fatores e apesar do solo sob pastagem diferir quanto ao grau de floculação, Tabela 3, ele se equiparou ao solo de cerrado nativo na conservação de macroagregados ( $>2 \mathrm{~mm})$ (Figura 3A); já para a condição de monocultivo de soja houve acréscimo de microagregados além de diferir significativamente para todas as classes de agregados. Outrossim, a matéria 
Tabela 3. Valores médios de matéria orgânica e grau de floculação de um Latossolo Vermelho-Amarelo em função dos diferentes manejos e camadas

\begin{tabular}{|c|c|c|c|}
\hline \multirow{2}{*}{ Manejo } & \multicolumn{3}{|c|}{ Camada (m) } \\
\hline & $0-0,10$ & $0,10-0,20$ & $0,20-0,30$ \\
\hline \multicolumn{4}{|c|}{ Matéria orgânica $\left(\mathrm{g} \mathrm{dm}^{-3}\right)$} \\
\hline Cerrado & $16,34 a^{1}$ & $15,94 \mathrm{a}$ & $16,66 \mathrm{a}$ \\
\hline Pastagem & $14,76 \mathrm{a}$ & $12,38 \mathrm{a}$ & $11,16 \mathrm{~b}$ \\
\hline Soja & $8,28 \mathrm{~b}$ & $8,06 \mathrm{~b}$ & $6,72 \mathrm{c}$ \\
\hline $\operatorname{CV}(\%)^{2}$ & 20,73 & 20,34 & 13,38 \\
\hline \multicolumn{4}{|c|}{ Grau de floculação (\%) } \\
\hline Cerrado & $42,42 \mathrm{a}$ & $39,44 \mathrm{a}$ & $40,68 \mathrm{a}$ \\
\hline Pastagem & $29,93 \mathrm{~b}$ & 30,35 b & 27,22 b \\
\hline Soja & $31,25 b$ & $27,18 \mathrm{~b}$ & $26,23 \mathrm{~b}$ \\
\hline $\mathrm{CV}(\%)^{2}$ & 9,25 & 11,26 & 14,43 \\
\hline
\end{tabular}

${ }^{2} \mathrm{CV}(\%)$ - coeficiente de variação

orgânica parece exercer uma função importante na aglutinação das partículas e na estabilização dos agregados do solo, tanto pela elevada área superficial (ligações entre polímeros orgânicos e superfícies inorgânicas) quanto pelo baixo valor de massa específica (Ekwue \& Stone, 1995; Braida et al., 2006) já que os valores médios de densidade do solo estimados pelas curvas de ajuste sofreram redução, em especial sob cerrado e pastagem, Tabela 4, não tendo sido alterados os valores de umidade de compactação considerando-se o mesmo solo (Tabela 5).

Tabela 4. Valores médios de densidade do solo, estimados pela curva de ajuste com (CR) e sem reúso (SR) de amostras de um Latossolo Vermelho-Amarelo sob diferentes manejos

\begin{tabular}{lccc}
\hline \multicolumn{1}{c}{ Manejo } & CR & SR & CV \\
Cerrado & \multicolumn{2}{c}{$0-0,10 \mathrm{~m}$} & \\
Pastagem & $1,51 \mathrm{a}$ & $1,48 \mathrm{~b}$ & 8,38 \\
Soja & $1,55 \mathrm{a}$ & $1,48 \mathrm{~b}$ & 6,36 \\
\hline \multicolumn{5}{c}{$0,10-0,20 \mathrm{~m}$} \\
Cerrado & $1,53 \mathrm{a}$ & $1,54 \mathrm{a}$ & 8,24 \\
Pastagem & $1,53 \mathrm{a}$ & $1,51 \mathrm{~b}$ & 7,59 \\
Soja & $1,58 \mathrm{a}$ & $1,53 \mathrm{~b}$ & 4,84 \\
\hline \multicolumn{5}{c}{$0,56 \mathrm{a}$} & $1,54 \mathrm{~b}$ & 8,00 \\
Cerrado & $1,61 \mathrm{a}$ & $1,56 \mathrm{~b}$ & 5,30 \\
Pastagem & $1,60 \mathrm{a}$ & $1,57 \mathrm{~b}$ & 5,93 \\
Soja & $1,58 \mathrm{a}$ & $1,54 \mathrm{~b}$ & 7,85 \\
\hline Médias seguidas da mesma letra na horizontal não se diferenciam pelo teste Tukey $(\mathrm{P}<0,05) ;$ \\
CV(\%) - coeficiente de variação
\end{tabular}

Neste estudo não foram comparados, estatisticamente, os pares de $\mathrm{U}_{\text {ótima }}$ e $\mathrm{Ds}_{\text {máx }}$ de compactação entre as camadas e manejos avaliados com e sem reúso de amostra pela inviabilidade relatada na metodologia. No entanto, com os valores médios de densidade do solo, Tabela 4, e umidade, Tabela 5, estimados pela curva de ajuste com e sem reúso de amostra para cada camada e manejo avaliados, pôde-se compreender que, comparado ao ensaio com reúso, o deslocamento das curvas sem reúso de amostras foi significativo uma vez que considerou os valores tanto antes quanto depois do vértice da parábola da curva de compactação.

No geral e em comparação com a condição natural, foram constatadas reduções de macroagregados $(>2 \mathrm{~mm})$ para ambas as situações, isto é, sem e com reúso de amostras (Figura $3 \mathrm{~B}$ e $3 \mathrm{C}$ ) respectivamente. No entanto, o processo de reúso de amostras potencializou a fragmentação dos agregados
Tabela 5. Valores médios de umidade do solo estimados pela curva de ajuste com (CR) e sem reúso (SR) de amostras de um Latossolo Vermelho-Amarelo sob diferentes manejos

\begin{tabular}{llrl}
\hline \multicolumn{1}{c}{ Manejo } & CR & SR $^{3}$ & CV \\
Cerrado & \multicolumn{2}{c}{$0-0,10 \mathrm{~m}$} & \\
Pastagem & $0,14 \mathrm{a}$ & $0,14 \mathrm{a}$ & 33,17 \\
Soja & $0,14 \mathrm{a}$ & $0,15 \mathrm{a}$ & 34,09 \\
\multicolumn{5}{c}{$0,13 \mathrm{a}$} & $0,13 \mathrm{a}$ & 40,20 \\
\hline \multicolumn{4}{c}{$0,10-0,20 \mathrm{~m}$} \\
Cerrado & $0,13 \mathrm{a}$ & $0,13 \mathrm{a}$ & 31,27 \\
Soja & $0,11 \mathrm{a}$ & $0,12 \mathrm{a}$ & 37,95 \\
\multicolumn{5}{c}{$0,12 \mathrm{a}$} & $0,12 \mathrm{a}$ & 38,70 \\
\hline Cerrado & $0,13 \mathrm{a}$ & $0,13 \mathrm{a}$ & 31,27 \\
Pastagem & $0,12 \mathrm{a}$ & $0,12 \mathrm{a}$ & 29,03 \\
Soja & $0,12 \mathrm{a}$ & $0,12 \mathrm{a}$ & 31,27 \\
\hline
\end{tabular}

Médias seguidas da mesma letra na horizontal não se diferenciam pelo teste Tukey $(P<0,05)$; CV (\%) - coeficiente de variação

existentes de vez que, observando as curvas granulométricas (Figura 2A, 2B e 2C) constata-se a proporção de acúmulo semelhante para areia muito fina, fina e média sendo que foi justamente nesta faixa que houve deslocamento dos resultados de análise de agregados via tamisamento úmido com reúso de amostra (Figura 3C). Portanto, isso aumentou a área de contato das partículas sólidas e, consequentemente, a $\mathrm{Ds}_{\text {máx }}$ de compactação, Figura 1, e os valores médios estimados pelas curvas de ajuste (Tabela 4).

Assim, a escolha do método para determinar a curva de compactação do solo depende do tipo de aplicação, ou seja, se geotécnico ou agronomicamente. Este aspecto é particularmente importante pois em condições naturais e mesmo após uso antrópico, no caso sob monocultivo de soja e pastagem a estrutura do solo e, em consequência, os agregados, não são totalmente fracionados (Figura 3A). Apesar dos dois métodos, com e sem reúso, conduzirem a pares de $\mathrm{U}_{\text {ótima }}$ e $\mathrm{Ds}_{\text {máx }}$ de compactação, agronomicamente a curva de compactação do solo em áreas agrícolas é adequadamente caracterizada sem reúso de amostras em razão de certa manutenção dos agregados das amostras compactadas no ensaio de Proctor (Figura 3B).

Observou-se também que o distanciamento das curvas de compactação com reúso e sem reúso é maior na condição sob cerrado e nas camadas de 0,20 a $0,30 \mathrm{~m}$ dando um indicativo de que, onde a estrutura natural está mais preservada ou que tenha sofrido pouca ou nenhuma pressão prévia de compactação, o reúso da amostra leva a erros mais expressivos.

Esses resultados reforçam a ideia de que há alteração estrutural do solo pelo reúso das amostras, independentemente do manejo e da camada avaliados. Além disto, também há tendência de acréscimo da densidade máxima de compactação em profundidade, seja com ou sem reúso de amostras, tendo ocorrido um efeito foi mais pronunciado com o reúso de amostra. Sabe-se que a $\mathrm{Ds}_{\text {máx }}$ de compactação é modificada pelo conteúdo de argila e matéria orgânica do solo (Braida et al., 2006; Marcolin \& Klein, 2011); no entanto, conforme o presente trabalho, ela é também adequadamente caracterizada sem reúso de amostra, daí a importância de se considerar este procedimento pois a "densidade relativa limitante" para o pleno desenvolvimento das plantas é dependente da $\mathrm{Ds}_{\text {máx }}$ de compactação. 


\section{CONClusões}

1. Independentemente dos sistemas de manejo e camadas avaliados, foram obtidas diferentes curvas de compactação do solo para os ensaios com reúso e sem reúso de amostras.

2. O procedimento de reúso aumenta a densidade máxima de compactação do solo pela fragmentação dos agregados e reorganização das suas partículas.

3. Em condições agrícolas a curva de compactação do solo é adequadamente caracterizada sem o reúso de amostras uma vez que, sob vegetação nativa e mesmo após uso antrópico, os agregados do solo não são totalmente fracionados.

\section{Literatura Citada}

ABNT - Associação Brasileira de Normas Técnicas - NBR 7182/86. Solo: Ensaio de compactação. Rio de Janeiro: ABNT, 1986. 10p.

Aragón, A.; García, M. G.; Filgueira, R. R.; Pachepsky, Y. A. A. Maximum compactibility of Argentine soils from the Proctor test; the relationship with organic carbon and water content. Soil and Tillage Research, v.56, p.197-204, 2000.

Banzato, D. A; Kronka, S. N. Experimentação agrícola. Jaboticabal: FUNEP, 1992. 247p.

Barzegar, A. R.; Nadian, H; Heidari, F.; Herbert, S. J.; Hashemi, A. M. Interaction of soil compaction, phosphorus and zinc on clover growth and accumulation of phosphorus. Soil and Tillage Research, v.87, p.155-162, 2006.

Beutler, A. N.; Silva, M. L. N.; Curi, N.; Ferreira, M. M.; Pereira Filho, I. A.; Cruz, J. C. Agregação de Latossolo Vermelho distrófico típico relacionada com o manejo na região dos cerrados no estado de Minas Gerais. Revista Brasileira de Ciência do Solo, v.25, p.129-136, 2001.

Botta, G. F.; Pozzolo, O.; Bomben, M.; Rosatto, H. Rivero, D.; Ressia, M.; Tourn, M.; Soza, E.; Vazquez, J. Traffic alternatives for harvesting soybean (Glycine max L.): Effect on yields and soil under a direct sowing system. Soil and Tillage Research, v.96, p.145-154, 2007.

Braida, J. A.; Reichert, J. M.; Veiga, M. Da; Reinert, D. J. Resíduos vegetais na superfície e carbono orgânico do solo e suas relações com a densidade máxima obtida no ensaio Proctor. Revista Brasileira de Ciência do Solo, v.30, p.605-614, 2006.

Dias Júnior, M. S.; Miranda, E. E. V. Comportamento da curva de compactação de cinco solos da região de Lavras (MG). Ciência e Agrotecnologia, v.24, p.337-346, 2000.

Ekwue, E. J.; Stone, R. J. Organic matter effects on the strength properties of compacted agricultural soils. Transactions of the American Society of Agricultural and Biological Engineers, v.38, p.357-3365, 1995.
EMBRAPA - Empresa Brasileira de Pesquisa Agropecuária (Brasil). Manual de métodos de análises de solo. Rio de Janeiro: Centro Nacional de Pesquisa de Solos, 2.ed., 1997. 212p.

EMBRAPA - Empresa Brasileira de Pesquisa Agropecuária (Brasil). Sistema brasileiro de classificação de solo. 2.ed. Rio de Janeiro: EMBRAPA Solos, 2006. 306p.

Garcia, R. A.; Rosolem, C. A. Agregados em um Latossolo sob sistema plantio direto e rotação de culturas. Pesquisa Agropecuária Brasileira, v.45, p.1489-1498, 2010.

Hamza, M. A.; Anderson, W. K. Soil compaction in cropping systems: a review of the nature, causes and possible solutions. Soil and Tillage Research, v.82, p.121-145, 2005.

Klein, V. A. Densidade relativa - Um indicador da qualidade física de um latossolo vermelho. Revista de Ciências Agroveterinárias, v.5, p.26-32, 2006.

Marcolin, C. D.; Klein, V. A. Determinação da densidade relativa do solo por uma função de pedotransferência para a densidade do solo máxima. Acta Scientiarum. Agronomy, v.33, p.349-354, 2011

Raghavan, G. S. V.; Alvo, P.; Mckyes, E. Soil compaction in agriculture: A review toward managing the problem. Advances in Soil Sciences, v.11, p.1-36, 1990.

Reinert, D. J.; Albuquerque, J. A.; Reichert, J. M.; Aita, C.; Andrada, M. M. C. Limites críticos de densidade do solo para o crescimento de raízes de plantas de cobertura em Argissolo Vermelho. Revista Brasileira de Ciência do Solo, v.32, p.1805-1816, 2008.

Salton, J. C.; Mielniczuk, J.; Bayer, C.; Boeni, M.; Conceição, P.S.; Fabrício, A. C.; Macedo, M. C. M.; Broch, D. L. Agregação e estabilidade de agregados do solo em sistemas agropecuários em Mato Grosso do Sul. Revista Brasileira de Ciência do Solo, v.32, p.11-21, 2008.

Santos, G. A. dos; Dias Junior, M. S.; Guimarães, P. T. G.; Furtini Neto, A. E. Diferentes graus de compactação e fornecimento de fósforo influenciando no crescimento de plantas de milho (Zea mays L.) cultivadas em solos distintos. Ciência e Agrotecnologia, v.29, p.740-752, 2005.

Silva, G. J.; Maia, J. C. S.; Bianchini, A. Crescimento da parte aérea de plantas cultivadas em vaso, submetidas à irrigação subsuperficial e a diferentes graus de compactação de um Latossolo Vermelho-Escuro distrófico. Revista Brasileira de Ciência do Solo, v.30, p.31-40, 2006.

Tisdall, J. M. Possible role of soil microorganisms in aggregation in soils. Plant and Soil, v.159, p.115-121, 1994.

Weirich Neto, P. H; Rosa, A. L. T. da; Gomes, J. A. Suscetibilidade de dois tipos de solos à compactação. Revista Brasileira de Engenharia Agrícola e Ambiental, v.6, p.349-353, 2002. 